\title{
Estudios de Asia y África
}

Estudios de Asia y África

ISSN: 0185-0164

reaa@colmex.mx

El Colegio de México, A.C.

México

Botton Beja, Flora; Cornejo, Romer Alejandro

Gao Xingjian, un escritor chino en el exilio

Estudios de Asia y África, vol. XXXVI, núm. 2, mayo-agosto, 2001, pp. 295-314

El Colegio de México, A.C.

Distrito Federal, México

Disponible en: http://www.redalyc.org/articulo.oa?id=58636205

- Cómo citar el artículo

- Número completo

- Más información del artículo

- Página de la revista en redalyc.org

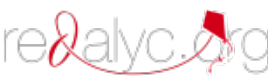

Sistema de Información Científica

Red de Revistas Científicas de América Latina, el Caribe, España y Portugal Proyecto académico sin fines de lucro, desarrollado bajo la iniciativa de acceso abierto 
China-literatura Gao Xingjian Premio Nobel

\title{
GAO XINGJIAN, UN ESCRITOR CHINO EN EL EXILIO
}

\author{
FLORA BOTTON BEJA \\ ROMER ALEJANDRO CORNEJO \\ El Colegio de México
}

En el número de marzo-abril del 2000 de la revista bimestral Xiaoshuo jie (Mundo de ficción), el escritor Wang Meng publicó un artículo en el cual hacía una evaluación del momento actual de la literatura china. En ese artículo se refiere a las críticas que se le han hecho a la creación literaria después de 1949, las cuales, aseveran que la literatura actual no tiene la grandeza que encontramos en los escritores chinos anteriores al triunfo de la revolución. Esta situación, según los detractores de la literatura contemporánea, le había significado a China que ningún escritor de esta nacionalidad hubiera sido merecedor del premio Nobel de Literatura. Wang Meng no compartía dicha visión pesimista y afirmaba que cada autor es producto de su época histórica y que es posible la creación de obras maestras equiparables a las grandes obras de la literatura tradicional siempre que haya un espacio para la actividad del espíritu y la apertura necesaria que le permita crear.

El 12 de octubre de ese mismo año, Gao Xingjian, un escritor chino, ${ }^{1}$ recibió el premio Nobel de Literatura. Xingjian nació en China y gran parte de su obra la gestó y la escribió en ese país, aunque tuvo que salir de él para encontrar el espacio necesario para continuar su trabajo creativo. En el mundo hispanohablante se conoce poco la literatura china contemporánea, una razón fundamental de ello es el prejuicio existente respecto a

Este artículo fue recibido por la dirección de la revista el 19 de febrero de 2001 y aceptado para su publicación el 15 de mayo de 2001.

${ }^{1}$ Nació el 4 de enero de 1940, en Ganzhou, provincia de Jiangxi, su familia provenía de Taizhou, en la misma provincia. Se graduó en 1962 en el Instituto de Lenguas Extranjeras de Beijing en Francés. Empezó a publicar en 1979. 
que la verdadera creación literaria no es posible por el peso aplastante del Estado, por lo que es escaso el número de investigadores interesados en ella, lo cual a su vez ha impedido una investigación minuciosa que revele los innumerables creadores que han trabajado y siguen trabajando en medio del acoso del Estado. En su momento Gao Xingjian fue un ejemplo de ello.

Si bien la servidumbre de la literatura ante las consignas políticas ha sido una constante en la historia contemporánea de China, a partir de 1978, después de la muerte de Mao Zedong y la caída de la facción "ultra izquierdista" de la llamada "banda de los cuatro", floreció en China una literatura más audaz y menos sujeta a las normas del realismo socialista. En el Cuarto Congreso de Escritores y Artistas, del 30 de octubre de 1979, a pesar de las tensiones y contradicciones entre burócratas de la cultura y creadores verdaderos, se respiraba un aire de optimismo y de esperanza. Se discutieron y fijaron normas y directrices para la creación artística y literaria de China en los próximos años. Los dirigentes prometieron mayor libertad de expresión y de creación, tolerancia para formas literarias y artísticas tradicionales y aún occidentales y la apertura a contactos con el mundo exterior. En esta misma ocasión, el escritor Bai Hua lanzó preguntas que estremecieron los principios mismos de las consignas literarias de la revolución cultural: ¿Debemos acaso ocultar las contradicciones sociales que no pueden ser disimuladas? ¿Debemos acaso cantar loas a la ignorancia que tanto le ha costado a nuestro país?" Refiriéndose a lo que una gran cantidad de asistentes ha sufrido en carne propia dice: "Mucha gente honrada perdió su puesto, su libertad, su pan de todos los días y hasta su vida, mientras que muchos hipócritas ganaron fama, dinero y puestos oficiales, no por su trabajo, sino por su habilidad para atemorizar a los demás". ${ }^{2}$ En este clima de creación, muchos escritores y artistas enriquecieron el ambiente cultural de China de una manera que no había sido vista desde las primeras décadas del siglo Xx, se experimentó con todo tipo de corrientes propias y extranje-

${ }^{2}$ Flora Botton Beja, "Cuarto Congreso de Escritores y Artistas de la República Popular China: Informe y comentarios, Estudios de Asia y África, vol. XVI, núm. 2(48), 1980, pp. 356-357. 
ras, fue el momento cuando Gao Xingjian se empezó a conocer en el país.

\section{De sus años de formación}

Gao Xingjian es un espíritu cercado por la realidad. Nació y se crió en medio de las guerras de su país, a sus nueve años ya estaba con su familia instalado en Nanjing, esa gran ciudad que había sido escenario del intento fallido de nacimiento de la república china moderna. Allí vivió la educación preuniversitaria en medio del entusiasmo comunista. A los 17 años se dirigió a Beijing a emprender la búsqueda solitaria de la paz interior que impregnaría su obra. Su camino temprano: el francés, la cultura francesa, el otro, una lente diferente, una trinchera aparentemente lejana desde donde dar sentido al caos. Se sumergió con avidez en lo que la cultura francesa podía ofrecerle, allí encontró el existencialismo, que en su obra se funde con la aproximación daoísta de la tradición filosófica propia, encontró el llamado teatro del absurdo, que le daría un sentido a su cotidianidad.

Las vicisitudes de su país le ofrecieron a Gao en un bloque comprimido, durante su juventud, todas las experiencias políticas posibles. Primero observó ese gran movimiento de "las cien flores", que incitaba a la expresión artística, intelectual y científica, que desembocó un año después en una reacción del Estado contra la libre expresión en las ciencias y las artes, lo que obligó a muchos intelectuales a "reeducarse" en el campo durante años. Su propia madre, alguna vez actriz aficionada, se marchó como voluntaria a una granja estatal donde murió ahogada en 1961. A los 18 años el país entero se sumergió en la euforia de políticas comunalistas radicales que supuestamente llevarían a China al desarrollo en poco tiempo, lo que culminó en un estrepitoso fracaso y hasta en hambrunas. Tenía 25 años cuando estalló la gran revolución cultural, un enorme movimiento de masas urbano que a la par que renovaba la dirigencia política, condujo a los jóvenes a una gran rebelión contra la cultura establecida, la impuesta hasta ese momento por el partido y la de las antiguas escuelas de pensamiento y 
arte. Gao mismo participó en los inicios de este movimiento, antes de que las luchas faccionalistas predominaran sobre el idealismo inicial. ${ }^{3} \mathrm{Su}$ esposa lo denunció y el matrimonio terminó en divorcio. En ese marco, a los 29 años, Gao Xingiiang fue enviado a reeducarse a los campos del suroeste de China; corría el año 1969 y Gao ya tenía una sólida cultura, por eso su reeducación sí fue posible, no como el partido hubiera querido, pero sí en las tradiciones literarias orales de las orillas del Yangzi, allí se gestó su obra "Hombre salvaje", estrenada en 1985. Sobre este periodo de su vida Gao dice: "Yo puedo decir que comencé a convertirme en escritor a partir del momento en que fui enviado al campo, para mi pretendida reeducación ideológica: yo tomé conciencia de mi pulsión por la escritura en el momento en que se me prohibió [...]"4 Ése fue el mundo que nutrió la juventud de Gao Xingjian, pleno de ideales políticos trastocados en miseria humana, el de la búsqueda de la distribución material colectiva y de la castración de la imaginación creativa individual. Su refugio: la compañía de su espíritu inquisitivo en la naturaleza humana, en las expresiones cotidianas de las representaciones del mundo del hombre sencillo $\mathrm{y}$, por supuesto, las lecturas furtivas y los apuntes incansables donde iba construyendo el único mundo posible, el propio. Un largo recorrido para regresar a la búsqueda intimista, individual, solitaria, que durante siglos había sido el camino de los grandes poetas, escritores y artistas de China, igualmente cercados por los tentáculos de un estado autoritario que se alimentaba de hacer del intelectual un funcionario.

\section{Gao Xingjian y la apertura de China}

La madurez de Gao coincide con la apertura de China al exterior y con la liberalización económica. En 1978, acompañó al gran escritor Ba Jin a Francia, en 1980 regresó a ese país y pasó por Italia con el poeta Ai Qing. En esta época de efervescen-

\footnotetext{
${ }^{3}$ Gao Xingjian y Denis Bourgeois, Au Plus Près du Réel, París, Ëditions de l'Aube, 1997, p. 19.

${ }^{4}$ Gao Xingjian y Denis Bourgeois, op. cit., p. 11.
} 
cia, en el marco del Cuarto Congreso de Escritores y Artistas, regresaron a Beijing muchísimos escritores que habían sufrido censura y persecución a fines de los años cincuenta, algunos veteranos, como Ding Ling, Ai Qing, otros mas jóvenes como Wang Meng y Bai Hua. También llegaron los "jóvenes instruidos" enviados al campo como consecuencia de la revolución cultural. Todos ellos habían vivido un exilio que, si bien los aislaba del centro, tuvo la virtud de ponerlos en contacto con una periferia que era conocida para la élite intelectual de los centros urbanos sólo como objeto de estudio antropológico, más que como una realidad del mismo país. A mediados de los años ochenta surgió un movimiento literario llamado shungen, "buscando las raíces" al cual se adhirieron con entusiasmo escritores jóvenes. Estos escritores, por alguna razón "sentían la necesidad de buscar la fuente de sus propias raíces culturales - y por ende, de su creatividad - en áreas que no fueran el centro político, tal y como estuvo representado por más de cuarenta años por la ideología maoísta y el Partido Comunista Chino". ${ }^{5} \mathrm{Al}$ mismo tiempo, la apertura a la literatura occidental, les ofrecía formas diversas y novedosas para expresarse. Las obras de escritores como Gabriel García Márquez y Juan Rulfo tuvieron una gran influencia sobre esos jóvenes, quienes se dejaban seducir por el realismo mágico en su afán de sublimación de un localismo no folclórico. Los estrictos controles políticos se relajaron y los intelectuales chinos creyeron que había llegado el momento de la eclosión de su creatividad por tanto tiempo contenida. Era entonces cuando Gao Xingjian regresaba de su exilio en el sur de China empapado de esta cultura local y fantástica y, gracias a su dominio del francés, pronto conoció la creación literaria occidental contemporánea.

En junio de 1981 Gao empezó a trabajar como escritor para el Teatro de las Artes del Pueblo de Beijing. La intelectualidad china vivía una explosión creativa y experimental que atrajo pronto la atención de la élite política que, como vimos,

\footnotetext{
${ }^{5}$ Leo Ou-fan Lee, "On the Margins of the Chinese Discourse: Some Personal Thoughts on the Cultural Meaning of the Periphery", en Gregory B. Lee (ed.) Chinese Writing and Exile, Chicago, The Center for East Asian Studies, The University of Chicago, 1993, p. 1.
} 
desde principios de 1980 venía alertando sobre la necesidad de "unidad y estabilidad" para lograr las Cuatro Modernizaciones.

A fines de 1981 la editorial Huacheng de Guangzhou publicó de Gao el trabajo "Estudio preliminar sobre el arte de la ficción moderna" (Xiandai xiaoshuo jiqiao chutan). Sobre dicho trabajo, Gao recibió el apoyo de escritores como Wang Meng, quien en junio de 1982 le escribió una carta abierta publicada en Xiaoshuo jie (Mundo de ficción), recomendando el libro y estimulando a Gao a continuar en el camino de la experimentación. Otros escritores como Liu Xinwu, Feng Jicai y Li Tuo hicieron lo propio y se abrió un gran debate sobre el modernismo en la literatura, que atrajo también la atención del gobierno sobre el escritor. Inevitablemente, Gao recibió una ola de críticas, por parte del establishment que le reprochaba sus referencias "extranjeras" como el existencialismo, el absurdo, el individualismo, etc. En éste y otros ensayos, Gao afirma que es inaceptable querer limitar la obra de ficción a una historia acabada, a un tema definido y con una secuencia lineal. Si se trata de reflejar la realidad en la ficción, es importante considerar que la vida no se comporta de esta manera, sino que es un ir y venir de momentos que deben ser captados, de situaciones que deben ser intuidas y el cine nos puede enseñar mucho para lograr este efecto. Para Gao, las técnicas que pueden ayudar a crear obras de ficción modernas son el fluir de la conciencia, el flash back, el juego con el tiempo, los sueños reveladores de la psicología de los personajes. Gao defiende su búsqueda de nuevas formas y afirma que utilizar técnicas diferentes a las tradicionales no le hace perder a la literatura china su carácter nacional. Algo importante es, sin duda, el uso de la lengua:

\footnotetext{
La lengua es el medio a través del cual pensamos y transmitimos nuestros pensamientos. Una obra escrita en la lengua de un nación reflejará naturalmente la tradición cultural de esa nación, su modo de vida y su pensamiento. Aunque un escritor chino emplee técnicas extranjeras, si escribe en un chino correcto y típico, su obra definitivamente tendrá un sabor nacional $[\ldots]$
}

y más adelante después de dar ejemplos de escritores chinos ilustres quienes escribieron siguiendo patrones y técnicas no chinas y que siguen siendo escritores indudablemente chinos, afirma: 
"La técnica artística trasciende las fronteras nacionales y no es el monopolio de una sola nación. El espíritu de una nación tiene su propia historia que es más fuerte y más duradera que la vida relativamente corta de una técnica". ${ }^{6}$ Gao no es el único en tomar en cuenta estas técnicas y vemos en escritores como Wang Meng una amplia utilización de estos elementos.

La primera de sus obras que fue puesta en escena fue "Señal de alarma", Juedui xinhao. Esta obra, escrita con Lui Huiyan, se basa en los recuentos de este último sobre algunos incidentes en trenes. "Señal de alarma", al principio censurada, se considera como la primera obra de teatro experimental en China. Se montó bajo la dirección de Lin Zhaohua, en octubre de 1982, en un pequeño auditorio en el Teatro de la Capital, Shoudu Juchang, en un escenario casi vacío que no se distinguía del resto del teatro, con el público sentado alrededor en el suelo, y con discusiones posteriores a la escenificación entre el público y los actores. El protagonista de la obra es un ladrón cuya convencional novia y un viejo obrero le hacen ver sus errores, y la escena transcurre en el carromato de custodia de un viejo tren de vapor. Independientemente del argumento, de su audaz puesta en escena, del minimalismo de la escenografía, del protagonismo de las luces y el sonido, esta obra marcó un parteaguas en el teatro chino contemporáneo: por primera vez se experimentaba con la ruptura de los patrones textuales y formales de lo que había sido el teatro institucional en China, experimentos ya desde hacía tiempo vistos en otras latitudes, y donde no podemos dejar de percibir algunas formas del teatro popular ambulante de China. "Señal de alarma" fue muy bien acogida por el público, llegó a cien representaciones y fue escenificada por otras compañías en varias partes del país.

La segunda puesta en escena de una obra de Gao fue la de "Una parada de autobús", Chezhan, en junio de 1983, a un mes de su publicación, en el mismo espacio y dirigida también por Lin Zhaohua. La obra fue suspendida después de diez funcio-

\footnotetext{
${ }^{6}$ Gao Xingjian, "Contemporary Technique and National Character in Fiction", Renditions, núms. 19-20, 1983.

7 Véase Flora Botton Beja, "Wang Meng y la nueva narrativa china", Estudios de Asia y África, vol. XIX, núm. 2, 1984 y Mabel Lee, "Without Politics: Gao Xingjian on Literary Creation", en The Stockholm Journal of East Asian Studies, vol. 6, 1995.
} 
nes. En ella se conjugan muchos elementos, por un lado no deja de recordar el espíritu de "Esperando a Godot" de Beckett, por otro lado utiliza, como lo había hecho Lao She en La casa de té, el lenguaje coloquial de Beijing y recupera en el personaje del "hombre silencioso" al protagonista de "El transeúnte" de Lu Xun. ${ }^{8}$ Cuando "Una parada de autobús" se escenificó, estuvo precedida por la puesta en escena del poema en prosa antes mencionado de Lu Xun, escrito en 1925 . En esta puesta en escena, el actor que figuraba como "transeúnte" se quedaba en el foro para encarnar al del "hombre silencioso". En la discusión al final de la representación, Gao eludió las referencias que el público hacía a la influencia de Beckett y prefirió referirse a las de Lu Xun, quien habiendo transitado en sus inicios por las corrientes del nihilismo, pasó luego a ser convertido por Mao en icono de la literatura revolucionaria.

En "Una parada de autobús" se narra la historia de un grupo de personas que durante años esperan en una parada de autobús entre un suburbio y una gran ciudad. Muchos autobuses pasan y ninguno para. Un hombre silencioso abandona al grupo, mientras el resto discute entre sí revelando sus sufrimientos e ilusiones. Al final se dan cuenta de su situación y deciden caminar a la ciudad sin lograrlo. Gao retrata la resignación pasiva, la indecisión y la superficialidad de la sociedad beijinesa, a través de sus personajes:

un viejo,

[...] los que se conforman con mirar el cielo desde el fondo de un charco, tarde o temprano lamentarán su error [...] Todo lo que quiero es que me caven un hoyo y que mi tumba diga: Aquí cayó un loco del ajedrez. No jugaba bien, pero le gustaba jugar. Nunca pudo enfrentar a un campeón [...] Murió como vivió: esperando.

un ama de casa,

¿Quién nos habrá hecho mujeres? Nuestro destino es esperar, siempre esperar. Primero que una babieca nos quiera ¡No es fácil lograrlo!

${ }^{8}$ Selected Works of Lu Hsun, vol. 1, Foreing Languages Press, Beijing, 1956, pp. 332-338. 
Después los hijos y luego que crezcan. En ese momento ya estamos viejas. ${ }^{9}$

La obra se mantiene con el tono de los diálogos de los personajes y al final, como para acentuar la inutilidad de la conversación, en el intento de los personajes de salir de su soledad, los siete actores que quedan se enfrascan en un monólogo simultáneo de nueve líneas, para finalmente retomar sus papeles y mantenerse en el mismo lugar.

La década de los ochenta fue difícil para los intelectuales. La apertura que permitió introducir a China, literatura, teatro, cine y arte occidental para avivar la creación propia inquietó a las autoridades que volvieron a dictar normas de pensamiento "correcto" para la creación literaria y artística, y esto dio lugar a críticas y censuras que ponían trabas a la libre expresión. En agosto de 1981 había empezado una campaña contra el escritor Bai Hua a quien se le acusó de pesimismo contrarrevolucionario por su obra "Amor amargo" y que continuó hasta el año siguiente. También fueron criticados escritores como Dai Houying, Sun Jingxuan y Yu Luojin. En este marco se inscribe la campaña contra la "contaminación espiritual" (1983-1984), catalogada como la más grande hasta ese momento después de la revolución cultural, que supuestamente fue causada por la "perniciosa" influencia occidental y fue avalada por Deng Xiaoping. El secretario general del Partido Comunista, Hu Yaobang, unió su voz a las críticas y dijo:

\footnotetext{
Los que difundan intencionalmente ideas venenosas y contradigan a nuestro sistema socialista, los que estimulen el culto y la adulación a lo extranjero [...] serán reprendidos por la opinión pública, y aquellos cuyas acciones tengan serias consecuencias serán perseguidos por la ley. ${ }^{10}$
}

Esta campaña, desarrollada al mismo tiempo en que se fomentaba la apertura económica, no puede dejar de recordarnos el movimiento de autofortalecimiento dirigido por intelectuales

\footnotetext{
${ }^{9}$ Los siguientes extractos fueron tomados de la traducción directa del chino de Jorge Svarzman de 1986.

10 "Algunos problemas en el frente ideológico que merecen atención", en Renmin Ribao, 2 de enero de 1983.
} 
conservadores a fines de la dinastía Qing que pretendían conservar la esencia china a través de los valores confucianos y rechazaban toda influencia occidental salvo para fines prácticos.

Gao no pasó inadvertido para las atentas autoridades chinas, quienes estaban pendientes de las críticas sociales que pudieran colarse entre la parafernalia de las innovaciones formales del teatro de vanguardia. Los críticos del partido catalogaron la obra "Una parada de autobus" como antisocialista, pues vieron en la espera inútil una referencia a la falta de confianza en el socialismo del autor, en cuyas ideas identificaron rápidamente la "contaminación" de las visiones del mundo burguesas, idealistas y egoístas, siempre atribuidas a corrientes extranjeras que se filtraban entre las numerosas importaciones de bienes de producción y de consumo que el país empezaba ávidamente a acoger en su reciente apertura. El crítico oficial $\mathrm{He}$ Wen percibe que el enojo, la frustración y la desesperación que sienten los personajes no se dirigen a la compañía de autobús, sino que reflejan

[...] todo tipo de malas prácticas y tendencias malsanas de nuestra sociedad: transporte desordenado, malos servicios, carencia de ciertos productos, corrupción, cohecho, malos modales, tráfico de influencias para conseguir un trabajo, educación rural pobre, etc. Al ver esta representación, sentimos que nuestras vidas están en un caos completo y que no hay esperanza para el futuro.

Es cierto que hay problemas en el país y en la sociedad, pero a pesar de las dificultades China lucha por salir adelante y

[...] los escritores y artistas deben reflejar de manera verídica esta lucha y su desarrollo. Es cierto que el arte debe también revelar el lado oscuro de la vida, pero esta revelación debe de hacer algo más que llamar la atención: debería privilegiar la confianza de encontrar un remedio. "Parada de autobús" no ha podido producir este efecto y en realidad ha fomentado la pérdida de la confianza.

En cuanto al hombre silencioso que según lo que insinúa Gao es una extensión del viajero en la obra de Lu Xun "El transeúnte", según He Wen, es una total falacia puesto que el personaje de $\mathrm{Lu}$ Xun es un personaje positivo que señala la nueva era por venir y está dispuesto a realizar sus ideales, mientras que el personaje en la obra de Gao, “'ipor qué”, se pregunta el crítico, "no 
le importa el sufrimiento del pueblo, no se une a las masas para cambiar la situación, sino simplemente adopta una actitud indiferente a los que lo rodean y sencillamente se marcha?" La mayoría de los creadores, insiste $\mathrm{He}$, siguen la línea del partido y avanzan con gran confianza, pero después de diez años de turbulencia y de recibir influencias nocivas de una ideología burguesa extranjera, algunos se desquiciaron y han producido obras "que distorsionan la historia, falsean los hechos, propagan todo tipo de ideas pesimistas, corruptas y vulgares, abogan por puntos de vista burgueses, idealistas, egoístas que tienen efectos nocivos sobre los lectores y los espectadores". ${ }^{11}$

Para la crítica occidental, cuando Gao escribió dicha obra el teatro del absurdo ya no era muy actual, además vieron en ella algo de imitación y la consideraron un poco rancia. Sin embargo, dice Geremie Barme que a pesar de que Gao habla de su deuda con Samuel Beckett, Ionesco y Antonin Artaud, no se trata de una versión china del significado de obras de esos autores. Es cierto que en Beckett los personajes esperan a Godot y que los de Gao están también esperando.

El autobús llega pero no se para, sin embargo, es más su propia culpa que otra cosa. Es cierto que se quedan esperando, pero tienen una aspiración que los dirige hacia algo y eso hace que su dilema no sea de ninguna manera existencial ni absurdo. Se trata mas bien de estrategia y de medios - cuándo y cómo deberían moverse. No existe duda alguna de que pueden y deben moverse hacia la ciudad. La obra de Gao no tiene como meta obligar al espectador a enfrentarse con los miedos semiconscientes y las ansiedades de la mente humana. En realidad, su visión positivista de la sociedad china contemporánea tiene un matiz moral: uníos y trabajen juntos, pero no deben descuidar el valor importante del individuo. Gao posiblemente se inspiró en Beckett e Ionesco, pero sus temas se mantienen dentro de la tradición didáctica de Ibsen y de Stanislavsky. ${ }^{12}$

${ }^{11}$ Véase "Postscript: On Seeing the Play The Bus-stop He Wen's Critique in Literary Gazette", en Stephen C. Soong y John Minford (eds.), Trees on the Mountain. An Anthology of New Chinese Writing, The Chinese University Press, Hong Kong, 1984, pp. 387-392.

${ }_{12}$ Geremie Barmé, "A Touch of the Absurd -introducing Gao Xingiian, and his play The Bus-stop", en Stephen C. Soong y John Minford (eds.), Trees on the Mountain. An Anthology of Nerw Chinese Writing, The Chinese University Press, Hong Kong, 1984, pp. 375-376. 
La apertura económica que promovió Deg Xiaoping finalmente tuvo consecuencias en la actitud hacia la cultura. Ya en octubre de 1983, Deng hizo un llamado para poner fin a la campaña de "contaminación espiritual" y a fines de diciembre de 1984, en un Congreso de la Asociación de Escritores chinos, los dirigentes del partido aseguraron que ya no habría censura ni represión y que la apertura hacia el exterior incluiría la literatura. Una semana más tarde, el 5 de enero de 1985, en una declaración oficial del partido, se prometió a los escritores otorgarles el derecho a "la democracia y a la libertad" y podían una vez más "florecer cien flores y competir las cien escuelas". Al mismo tiempo, para prevenir excesos, se les aconsejó aceptar el liderazgo del partido y las directrices del marxismo-leninismo. Sin embargo, sorprendentemente, en un discurso ese mismo mes, $\mathrm{Hu}$ Yaobang instó a jóvenes cuadros a no aceptar nunca más "estupideces radicales ultraizquierdistas" y se apoyó en los escritores Liu Binyan y Wang Meng quienes eran vicepresidentes de la Asociación de Escritores.$^{13}$ Esta situación permitió a Wang Meng en 1986 describir lo que consideraba ser el Estado ideal. Éste sería realista, constructivo y racional y a la vez respetuoso, flexible y reformista, un Estado en el cual "un escritor conserva el derecho a su propia imaginación y voluntad, sin doblegarse a la opresión política ni a la coerción administrativa ni tampoco a las recompensas monetarias" y agrega: "La libertad intelectual es un deber y a la vez un derecho". ${ }^{14}$ En este contexto se encontraba Gao Xingjian y muchos de sus colegas contemporáneos, quienes "lanzaron ataques conscientemente 'apolíticos' contra el autoritarismo del partido y a la vez trataban de forjar nuevos espacios para su creatividad artística". ${ }^{15}$

Este ambiente de enrarecimiento político pasó por la mirada hueca que Gao le dirigía a la política sin lograr que se mostrara aludido. En esos momentos, Gao fue erróneamente diag-

\footnotetext{
${ }^{13}$ Wang Meng fue ministro de cultura, pero cayó en desgracia después de 1989 y aún radica en China. Liu Binyan emigró a Estados Unidos y se convirtió en uno de los críticos más feroces del gobierno chino.

${ }^{14}$ Wang Meng, "The Imagination of the State", Chinese Literature, invierno, 1986, p. 188.

${ }^{15}$ Leo Ou-fan Lee, op. cit., p. 5.
} 
nosticado de cáncer de pulmón, ${ }^{16}$ enfermedad de la que había muerto su padre dos años antes, y mientras se aclaraba el diagnóstico se fue algunas semanas a Nanjing con su hermano. ${ }^{17}$ En medio de su enfrentamiento con la muerte y los rumores de que sería enviado por el gobierno a la lejana provincia de Qinghai, Gao pidió 400 yuanes a la Editorial del Pueblo de Beijing en adelanto por las regalías de su novela Lingshan (La montaña del alma) y se fue a la provincia de Sichuan. Allí emprendió un largo viaje de varios meses en el que recorrió unos $15000 \mathrm{~km}$ hasta la costa oriental. Éste fue un periodo para Gao de reencuentro con China, no sólo volvió a las aldeas campesinas donde había estado durante la revolución cultural, sino que también visitó los vestigios de los que habían sido grandes centros daoístas, monasterios budistas, las montañas que mil veces y de mil maneras habían filtrado por su alma los grandes pintores de China. Desde hoy podemos ver este viaje como una despedida, una recolección exhaustiva y cuidadosa del equipaje esencial que llevaría a su exilio dos años más tarde. Después de esta experiencia Gao regresó a Beijing y estimulado por Wang Mang publicó algunos cuentos. En octubre de 1984 escribió su obra "Hombre salvaje".

Como la puesta en escena de "Hombre salvaje", Yeren, se demoró debido a la campaña contra la contaminación espiritual, la primera presentación de ésta, se hizo en mayo de 1985, en la sala principal del Teatro de la Capital, con escenografía del escultor yunnanés Yin Guangzhong. En esta obra, con claro acento autobiográfico, Gao retrata a un intelectual de edad mediana que vive la ruptura de su matrimonio, el caos político y la desidia del gobierno local urbano. La obra prohibida fue poco después.

A fines de1985 Gao aceptó una invitación a Berlín y de allí realizó dos viajes a Francia. Regresó a Beijing a principios de 1986 y escribió La otra orilla Bi an, que fue censurada y únicamente se le permitió representarla sin diálogos. Después se escenificaría con éxito en Taiwan y Hong Kong. Ésta es una 1990, p. 73

${ }^{16}$ La referencia a este evento está en el capítulo 12 de Lingshan, Lianjing, Taipei, bolm Journal of East Asian Studies, vol. 6, 1995, p. 85. 
obra formalmente más audaz que las anteriores, que incursiona de una manera más contundente en el teatro total. En ausencia de una línea argumental previamente estructurada, el desarrollo de la obra descansa en un trabajo intenso de los actores con su relación entre sí, con su propia fantasía y con objetos de la escenografía. La técnica adquiere un papel protagónico a través del canto, la recitación, la mímica y el movimiento, lo que acerca a Gao a la opera tradicional china.

La caída en desgracia de $\mathrm{Hu}$ Yaobang, quien había protegido a algunos intelectuales liberales, desencadenó una nueva campaña contra el "liberalismo burgués" en 1987, que le costó a varios intelectuales perder la membresía del Partido Comunista. En 1987 Gao fue invitado a Alemania en donde permaneció varios meses y finalmente se fue a Francia, lugar en el cual radica todavía.

\section{El exilio}

Gao Xingjian es muy claro sobre esta condición que ha afectado a tantos intelectuales y artistas en todas las latitudes. "Ir al exilio, por supuesto, no es el propósito de nuestra existencia, es sólo un medio para protegerse uno mismo. Es más importante dirigirse a una forma de exilio espiritual de la opresión de la realidad". ${ }^{18}$

¿Hasta qué punto es Gao un escritor chino a pesar de su exilio en Francia? Gao responde en uno de sus ensayos a esta duda, desde su propia individualidad:

\footnotetext{
Yo soy sólo un escritor chino y no tengo manera de representar a los otros. Para mí, China no es la nación colosal y el Estado abstracto, sino el trasfondo cultural que se refleja en mis trabajos y la influencia que esa cultura ha ejercido sobre mí desde que nací, es también el modo de pensar inherente en la lengua china que escribo. Yo he adoptado también la cultura occidental y estoy muy interesado en las culturas de Asia, de África y de otras naciones. Que los escritores y artistas defiendan, en esta era de integración cultural, una cultura nacional

${ }^{18}$ Gao Xingjian, "The Voice of the Individual”, en The Stockholm Journal of East Asian Studies, vol.4, 1993, p. 78.
} 
pura no es más que un tipo de mitología, si no es que una consigna engañosa. ${ }^{19}$

Tanto él como otros escritores expatriados viven el dilema de escribir en una lengua diferente a la del país en el que viven, el de tener que inventar sus raíces desde el exterior, el de lidiar con influencias que retan su cultura original. Esto hace que se aferren a lo chino mucho más que cuando vivían en China, en donde adoptar ideas y formas extranjeras se hacía dentro de un contexto que al fin y al cabo les era familiar y en donde sus lectores e interlocutores hablaban el mismo idioma y compartían las mismas inquietudes. Un escritor chino en el exilio está impelido a crear obras que por un lado no traicionen estos orígenes tan difícilmente conservados y que a la vez sean comprensibles para un público universal. El estudioso sueco T. Loden habla del dilema al cual se han enfrentado los escritores chinos desde los principios de la era moderna, cuando la modernización del país era el elemento indispensable para resistir la embestida de las fuerzas colonizadoras, pero que al mismo tiempo corrían el peligro de ser despojados de su propia cultura. Pasaron así por épocas contradictorias: desde el movimiento de autofortalecimiento que aspiraba a encontrar la salvación en la tradición a veces reinterpretada, hasta los movimientos de Nueva Cultura y Cuatro de Mayo que rechazaban la tradición y querían un total rompimiento con el pasado confuciano, usaban la lengua vernácula y exaltaban el individualismo, pero la intención obvia era la de salvar a China y el total rechazo de sus tradiciones no era el camino más conveniente. Hasta 1949 los escritores trataron de buscar formas de ser chinos, pero valiéndose de instrumentos que podían provenir de otras partes. Muchos tuvieron que vivir en el exterior por razones políticas o simplemente para completar su educación. Entre los ejemplos más destacados están el escritor Lu Xun, quien radicó en Japón, y el poeta Wen Yido, quien vivió en Estados Unidos. Cuando en 1949 triunfó la Revolución, tanto el modernismo como el individualismo fueron criticados y se enfatizó la creación folclórica y popu- 
lar. Sin embargo, a pesar del valor que tuvo este rescate, al imbuirlo de un contenido políticamente correcto se "mató una gran parte de la cultura tradicional". ${ }^{20}$ A principios de los años ochenta, con la revaloración de aspectos de la cultura tradicional, incluyendo al confucianismo, se inició una vez más la discusión de los límites de lo que es chino propiamente dicho y una renovación cultural que adoptara formas occidentales.

Como consecuencia de la historia contemporánea de China y las exigencias de un nacionalismo omnipresente y compartido, un fenómeno peculiar de la literatura china es que se dan varios niveles de exilio, por un lado los escritores radicados en Taiwan y Hong Kong y por el otro los que viven en diferentes países occidentales, y todos convergen en la búsqueda de una identidad "china" que si bien puede tener variaciones tiene sus raíces en el reconocimiento de la misma cultura. Lo que $\mathrm{C}$. $\mathrm{T}$. Hsia (A History of Modern Chinese Literature) llama "la obsesión por China" compartida por varios escritores chinos en el exilio "es una obsesión que señala a los problemas de China como específicamente chinos y que exige la lealtad de los chinos en todas las partes del mundo". ${ }^{21}$ Gao ha tratado de zafarse, de alguna manera, de estas ataduras:

Yo considero un tanto cuestionable utilizar un nombre colectivo cuando se habla, y temo más ser sofocado por ese nombre colectivo sin articular una palabra. "Intelectuales chinos" es un nombre colectivo, el cual yo soy obviamente incapaz de representar y también temo que él me vaya a representar a mí de manera tal que yo desaparezca de la vista.

\section{Para Gao,}

estudiar la historia y la realidad de China es en cierta forma ubicarse uno mismo, pero no podemos cambiar la historia, ni cambiar al gigantesco país que es China, por lo tanto, más vale tratar de salvarnos primero nosotros mismos [...] La independencia y la soberanía del espíritu individual fue fácilmente devorada por la conciencia colectiva de la nación y de las clases sociales. ${ }^{22}$

${ }^{20}$ Torbjörn Lodén, "World Literature with Chinese Characteristics: On a Novel by Gao Xingjian", en The Stockolm Journal of East Asian Studies, vol. 4, 1993, p. 25.

${ }^{21}$ Leo Ou-fan Lee, op. cit., p. 11.

${ }^{22}$ Gao Xingjian, op. cit., pp. 71-73. 
Lejos de los barullos políticos, Gao ha continuado escribiendo con gran impulso en el exilio, en 1990 publicó en Taiwan su novela La montaña del alma, iniciada en 1982. Con una obvia referencia autobiográfica, Lingshan cuenta la historia de un escritor quien después de ser diagnosticado de cáncer terminal en los pulmones decide hacer un viaje por el sur de China y adentrarse en las culturas de las diversas nacionalidades de la región. El cáncer desaparece y el escritor continúa su plan de viaje por las provincias de Sichuan, Qinghai, y a lo largo del río Yangzi por las provincias de Jiangsu y Jiangxi. La obra es un recorrido complejo por la intimidad y la mirada de diversos narradores en la búsqueda del refugio interior en la montaña del alma, es un recorrido por los recovecos de los sentimientos y sensaciones de los personajes, que se entrelaza con las observaciones minuciosas a un mundo exterior habitado por la exuberancia de los paisajes, morada de diversos pueblos que son retratados en sus formas únicas de vida.

La situación que se suscitó después de los acontecimientos de Tiananmen en 1989 obligó a varios intelectuales a dejar China de modo voluntario o involuntario y comenzar una nueva vida en el exilio, esta vez un exilio fuera de las fronteras del país. Gao renunció al partido después de los acontecimientos violentos de junio de 1989 en Tiananmen y fue invitado a escribir una obra sobre ellos, ${ }^{23}$ el resultado fue "Los fugitivos", Taowang. Por encima de cualquier ente social, Gao fue fiel al individuo y mantuvo su mirada intimista. Si bien la obra tiene como marco los tanques y disparos de Tiananmen, se centra en tres personajes desconocidos entre sí quienes, ante la llegada de los tanques a la plaza, se refugian en la oscuridad de un almacén abandonado y con un diálogo que recuerda "A puerta cerrada" de Sartre confrontan sus ideas, sus vivencias y las razones que los han hecho encontrarse en esta situación precaria. Uno de los personajes, "el hombre maduro" se enfrenta con "el joven" quien le reprocha su falta de compromiso y entusiasmo por "la causa": "No quiero ser una baraja en manos de alguien, manipulado por otros; quiero tener mi libre albedrío, independiente y sólido" y más adelante, cuando

${ }^{23}$ Mabel Lee, op. cit., p. 89. 
el joven lo reta para que declare qué es: “¿Un individualista, un nihilista? Más vale que le diga que no soy ningún 'ista', no necesito adorar ningún 'ismo'. Soy simplemente un ser humano que no puede soportar la idea de ser masacrado ni orillado al suicidio". ${ }^{24}$ Esta obra no satisfizo a los militantes disidentes ni al gobierno de China que declaró al autor persona non grata.

Gao ha continuado escribiendo obras de teatro, cuentos y novela. La más reciente, Yigeren de shengjing, ${ }^{25} \mathrm{O}$ "La vida de un hombre solo", tiene como marco la revolución cultural y, como en La montaña del alma, hay una mezcla magistral de todo tipo de técnica literaria con referencias autobiográficas y disquisiciones filosóficas que lo revelan como un existencialista posmoderno.

Tú no eres un dragón, no eres un insecto, no eres ni lo uno ni lo otro, ese no ser, eso eres tú, ese no ser no es una negación, mejor dicho es una realización, una impronta, un gasto, un resultado, antes de un agotamiento total, es decir la muerte; tú no eres más que un mensaje de la vida, una expresión, una palabra dicha al no ser.

Tú has escrito este libro para ti, un libro sobre la huida, el Libro de un hombre solo, tú eres a la vez tu señor y tu apóstol, tú no te sacrificas por los demás ni pides que se sacrifiquen por ti, así es, no puede ser más justo $[\ldots]^{26}$

Gao Xingjian no se caracteriza por ser precisamente un disidente político: "No me opongo a que los intelectuales se comprometan con la política. Pero personalmente no pretendo hacerlo, aunque no me niego a expresar opiniones políticas." ${ }^{27} \mathrm{Su}$ cuestionamiento del sistema político en China lo ha hecho no tanto con declaraciones o panfletos si no con obras en donde los personajes a través de vivencias cotidianas reflejan su desazón, su inconformidad con el sistema. Su decisión de emigrar se debió más a un afán por conseguir un espacio de

${ }^{24}$ Gao Xingjian, "Fugitives, a Modern Tragedy in two Acts", en Gregory Lee (ed.), Chinese Writing and Exile, Chicago, The Center for East Asian Studies, The University of Chicago, 1993. francés.

${ }^{25}$ Yigeren de shengjing, Lianjing, Taipei, 1999, al año siguiente fue publicado en

${ }^{26}$ Gao Xingjian, Le livre d'un homme seul, Éditions L'Aude, París, 2000, pp. 220-221.

${ }^{27}$ Gao Xingjian, “The Voice of the Individual”, en op. cit., p. 77. 
creación sin trabas y sin condicionamientos, que a una necesidad de militancia política. Para mantener la libertad de su pluma, el escritor ha declarado que prefiere vivir de su obra pictórica, antes que de sus trabajos escritos.

El mismo escritor ha expresado directamente su posición sobre las pertenencias a alguna corriente política:

En esta época de colapso ideológico y de explosión teórica, con nuevas tendencias que se reemplazan unas a otras cada vez más rápido, ya no hay una corriente principal a la cual nos podamos acoger. Yo pienso que podríamos también llamar a esta época una "era sin ismos", debido a que las construcciones ideológicas ya han sido reemplazadas por métodos en continuo cambio. Si un individuo desea buscar un asidero en este mundo, me temo que lo único que le queda es la duda. Lo que quiero expresar con "duda" es un tipo de actitud, no un "ismo". Cuando un individuo está construyendo su propio mundo espiritual, la duda también es en cierta medida un punto de vista. Usar el lenguaje para llegar a la lógica no es muy confiable, ya que lo que las expresiones del lenguaje ofrecen es sólo una gama de posibilidades; el "yo" sólo existe en el entramado de las percepciones y es dependiente del lenguaje para existir. En otras palabras, la existencia del yo no es más que una expresión del lenguaje, y el yo sólo puede encontrar confirmación a través de la expresión de lo que hace único al lenguaje de uno, lo cual no necesita y no puede ser probado. Es a través del lenguaje que el individuo se mueve del campo obscuro del yo hacia el mundo y es capaz de comunicarse con otras personas; así, gracias a la ayuda de la razón, basada en la duda, evita la muerte inexplicable, el suicidio y la locura. ${ }^{28}$

Desde 1986 ninguna de sus obras ha sido puesta en escena de manera directa en China, lo que no significó que no fuera conocido en los círculos literarios donde la huella de su obra sigue estimulando la creación literaria. El poeta Yu Jian, basándose en Bi an, escribió en 1992 el texto Una discusión gramatical sobre "El otro lado", en la que se subvertía el texto de Gao, vaciándolo de su contenido dramático original. ${ }^{29}$ Esta obra

${ }^{28}$ Gao Xingjian, op. cit., p. 80.

${ }^{29}$ Claire Huot, "Here, There, Anywhere", en Michel Hockx (ed.), The Literary Field of Twentieth-Century China, University of Hawaii Press, Honolulú, 1999, pp. 211-215.

${ }^{30}$ Yu Jian, poeta, nació en 1954, vive en Kunming, es miembro de la Asociación de Escritores de Yunnan, trabaja como editor de la revista Yunnan wenyi pinglun. Ha publicado varios libros de poemas. Mou Sen es uno de los más importantes hombres del teatro experimental de China hoy, trabaja sus obras con Yu Jian. 
de Yu Jian fue puesta en escena por Mou Sen ${ }^{30}$ como obra poética en un acto durante una semana en febrero de 1993 en un aula del Instituto de Cinematografía de Beijing con gran éxito entre un público de artistas y escritores de vanguardia, después de lo cual se realizó un simposio. Éste fue un acontecimiento importante como el primer montaje en deconstrucción teatral en China. Jiang Yue filmó un documental, titulado $E l$ otro lado y Cui Jian, la super estrella del rock, escribió una canción con el mismo nombre.

Gao Xingjian se nutrió y creó gran parte de su obra entre los intersticios de un Estado interventor, y su huella sigue acompañando a muchos espíritus libres que moran en esas rendijas, mientras el aparato estatal se distrae aplacando manifestaciones y asegurando su permanencia con elevadísimas cifras macroeconómicas. Este cerco no es lejano al que muchos espíritus creativos viven en otros lados del mundo, donde el fantasma del Estado interventor se transmuta en las múltiples expectativas sociales hacia el intelectual y su sentimiento de obligación con ellas. En este sentido Gao responde desde la experiencia propia y la de la historia de sus ancestros, el resultado es que su reacción es rabiosamente individual, existencial, situando al intelectual en un estado permanente de alerta ante la alienación de las entelequias colectivas.

Dirección institucional de los autores:

Centro de Estudios de Asia y África

El Colegio de México, A.C.

Camino al Ajusco 20

Pedregal de Santa Teresa

10740 México, D.F. 